\title{
Breeding indicators of Carniolan (Apis mellifera carnica pollm) and Carpathy (Apis mellifera carpatica) honey bees
}

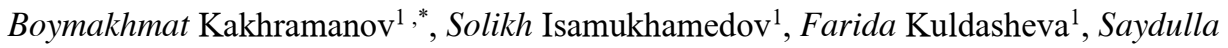 \\ Doniyorov $^{1}$, and Nilufar Rakhimjanova ${ }^{1}$ \\ ${ }^{1}$ Tashkent State Agrarian University, University str., 2, Tashkent province, Uzbekistan, 100140
}

\begin{abstract}
In our research, the adaptation of imported carniolan (Apis mellifera carnica Pollm) and Carpathian (Apis mellifera carpatica) honey bees to the natural climatic conditions of Uzbekistan, the main indicators of queen bees in experimental groups, the results of two-year assessment and economic benefits were studied for the first time in Uzbekistan.
\end{abstract}

\section{Introduction}

Ensuring the implementation of the Resolution of the President of the Republic of Uzbekistan dated October 16, 2017 No PP-3327 "On measures to further develop the beekeeping industry in the Republic" [1], as well as the organization of breeding in the beekeeping industry on a scientific basis is very important.

In addition, in order to increase the efficiency of beekeeping, further increase the volume and variety of honey production, to apply best practices in beekeeping in all regions of the country, imported bee species Carniolan (Apis mellifera carnica Pollm) and Carpathian (Apis mellifera carpatica) adaptation to the conditions, full use of their breeding characteristics, care of queen bees, scientific substantiation of the correct organization of supplementary feeding of bee families are now important [2-5].

\section{Materials and methods}

This research was conducted at the 'Artikovlar' beekeeping cluster in Kibray administrative district of Tashkent province, 'Gulomkhoja' beekeeping farm, 'Tashkent' bee agro farm, and the experimental farm of Tashkent State Agrarian University (TSAU) in accordance with the guidelines of the Research Institute of Beekeeping.

Genetic analysis of bee pedigree was studied on the basis of PTsR-diagnostic method (polymerization chain reaction) - (RAPD-technology). Studies have shown that these technologies are suitable for genetic certification of bee species. The bee families under study proved that they belong to the genus Carniolan (Apis mellifera carnica Pollm) and the Carpathians (Apis mellifera carpatica) [6].

\footnotetext{
* Corresponding author: b.kaxramanov@mail.ru
} 
In order to study the age of the queen bees, 10 bees were selected for each group from the bee families belonging to two species on the basis of analogs.

This study took into account the following: the age of the queen bees, the strength of the families, the number of frames in the hive, development, honey and perga were analyzed according to the factors studied [7-9]. For comparison, two-year-old mother bees from the control group and one-year-old mother bees were used for the experiment.

Assessing the economic usefulness of bee families was undertaken considering the developed methodology created by several international and regional researchers [10-13].

Honey yield was calculated according to control indicators [8]. At the end of the main honey harvest season, the amount of branded honey was determined by measuring on a VTM-100 scale. In assessing the criteria for the quality of honey was studied on the indicators used in paragraph 4.1.4 of 19792-2001 GOST.

Using student criteria for the data obtained, statistically processed according to the method, (R) value level, the calculations were correlated on a computer using MS OFFICE (Microsoft Excel) programs.

\section{Results and discussion}

\subsection{Assessment of bee families belonging to the species Carniolan (Apis mellifera carnica Pollm) and Carpathians (Apis mellifera carpatica)}

In assessing the bee family, the productivity of the family was taken into account the characteristics of honey, wax, migration, the degree of laying of queens, the family's winter hardiness, peace, family health and all the characteristics of this breed (Figure 1).

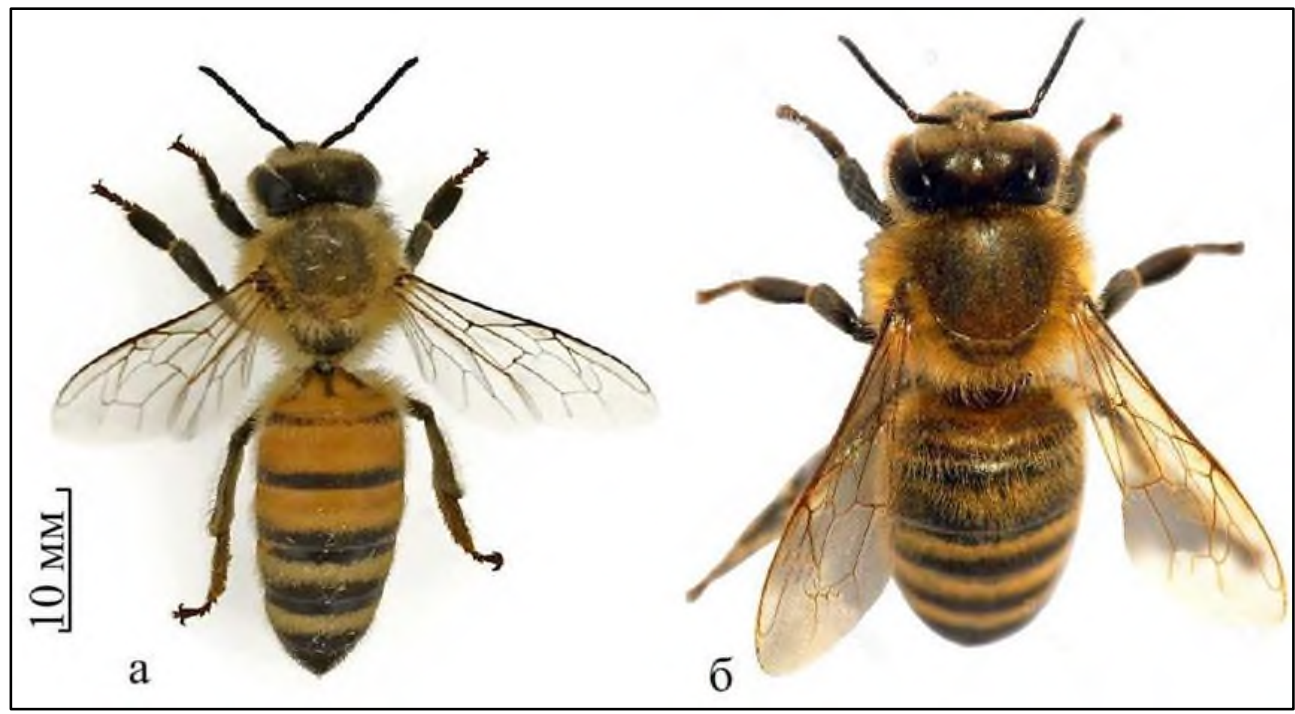

Fig. 1. Two types of honey bees: A - Carniolan (Apis mellifera carnica Pollm); B - Carpathians (Apis mellifera carpatica)

The main purpose of selecting and evaluating the bee family is to increase productivity, improve breeding traits, and reproduce them. Therefore, in the implementation of selection and breeding work in beekeeping is important to assess the quality of the bee family, especially the breeding of queen bees, the selection of its breeding value. In order to 
develop the beekeeping industry on the basis of rapid technologies, the selection and evaluation of bee families in breeding is of great practical importance.

In the selection and evaluation of the bee family, firstly, the productivity of the bee family was assessed, and secondly, the ability of the mother bees in this selected bee family to lay eggs daily was assessed. Also, during the experiment on these farms, all the economic and useful features of the bee family were directly studied and evaluated on the basis of zootechnical records in the beekeeping journal, the breeding value was determined and the relevant class categories were identified.

The morphological structure of bees in the experimental groups was analyzed. In this case, the characteristics of bees such as breed, behavior, external structure, biomass of queens and the number of eggs laid per day were studied (Table 1).

According to the results of our research, bees of the genus Carniolan (Apis mellifera carnica Pollm) act as a frame when their behavior is observed when the hive is monitored. The Romans, on the other hand, were observed to be disturbed as they passed through the fall. These indicators were observed in the Carpathian (Apis mellifera carpatica) breed sitting on the rum and peaceful when the rums were examined. The biennial average biomass of queen bees was $108 \pm 1 \mathrm{mg}$ in single-day queen bees of the Carniolan breed, or $13.4 \%$ compared to the Carpathian breed of the control group. Unfertilized queen bees were between $183 \pm 2.2 \mathrm{mg}$ or $1.1 \%$. Fertilized mother bees had a high rate of $200 \pm 4.2 \mathrm{mg}$ or $2.6 \%$.

In terms of one-day laying of queens, Carniolan bees also dominated, with an average two-year egg production of 1,890 \pm 7.1 eggs or 1,770 \pm 7.9 eggs compared to Carpathian bees, an increase of $6.8 \%$. These values were reliable in both groups $(\mathrm{R}>0.999)$.

The two-year average biomass of Carpathian queens was $105 \pm 1.4 \mathrm{mg}$ per day, the biomass of unfertilized queens was $181 \pm 2.3 \mathrm{mg}$, and the biomass of fertilized queens was $195 \pm 5.2 \mathrm{mg}$. It can be seen that Carniolan bees were $3 \mathrm{mg}$ higher in biomass per day than Carpathian queens, $2 \mathrm{mg}$ higher in biomass of unfertilized queens and $5 \mathrm{mg}$ higher in biomass of fertilized queens. It should be noted that the breed of bees belonging to both breeds meets the standard requirements in terms of biomass of mother bees and daily egg laying.

The effectiveness of bees belonging to the Carniolan and Carpathian breeds in our experiment is displayed in Figure 2.

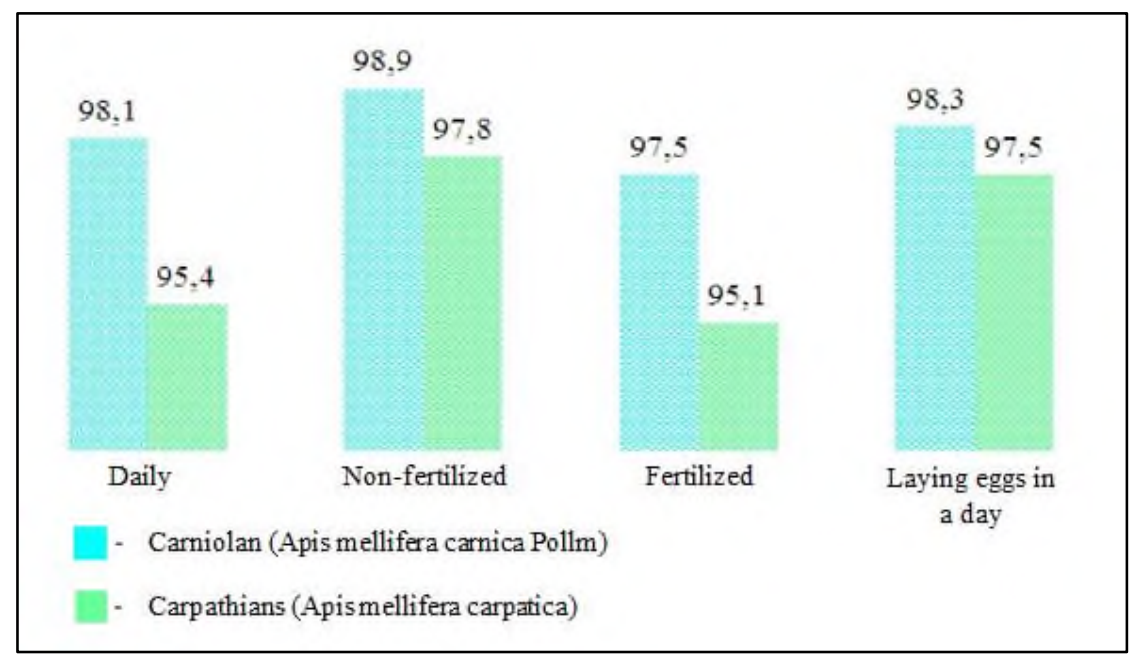

Fig. 2. Effectiveness of bees belonging to the Carniolan and Carpathian breeds 
Table 1. Main indicators of mother bees in the experimental groups (n-50)

\begin{tabular}{|c|c|c|c|c|c|c|c|c|c|c|c|}
\hline \multirow{3}{*}{ \# } & \multirow{3}{*}{ 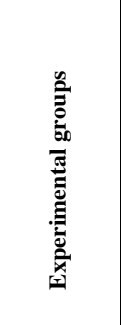 } & \multicolumn{2}{|c|}{ Behavior } & \multicolumn{6}{|c|}{ Biomass of mother bees, $\mathrm{mg}$} & \multicolumn{2}{|c|}{ Laying eggs, day } \\
\hline & & \multirow{2}{*}{ 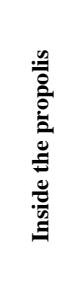 } & \multirow{2}{*}{ 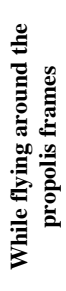 } & \multicolumn{2}{|c|}{ Daily } & \multicolumn{2}{|c|}{ Not fertilized } & \multicolumn{2}{|c|}{ Fertilized } & & \\
\hline & & & & $\begin{array}{l}(\mathbf{L i m}) \\
\mathbf{X} \pm \mathbf{S x}\end{array}$ & $\begin{array}{l}\mathrm{Cv}, \\
\%\end{array}$ & $\begin{array}{c}(\mathbf{L i m}) \\
\mathbf{X} \pm \mathbf{S x}\end{array}$ & $\begin{array}{c}\text { Cv, } \\
\%\end{array}$ & $\begin{array}{c}(\mathbf{L i m}) \\
\mathbf{X} \pm \mathbf{S x}\end{array}$ & $\begin{array}{l}\mathrm{Cv}, \\
\%\end{array}$ & $(\operatorname{Lim}) \mathbf{X} \pm \mathbf{S x}$ & $\begin{array}{l}\mathbf{C v} \\
, \%\end{array}$ \\
\hline \multirow{3}{*}{1} & 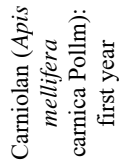 & 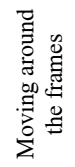 & 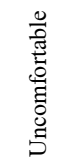 & $\begin{array}{c}(98-119) \\
109 \pm 1.1\end{array}$ & 4.2 & $\begin{array}{c}(163-198) \\
184 \pm 2.2\end{array}$ & 4.5 & $\begin{array}{c}(178-218) \\
202 \pm 3.1\end{array}$ & 4.8 & $\begin{array}{c}(1,842-2,113) \\
1,920 \pm 7,3\end{array}$ & 7,6 \\
\hline & 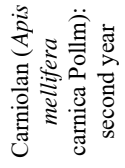 & 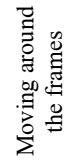 & 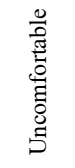 & $\begin{array}{l}(96-116) \\
107 \pm 0.9\end{array}$ & 4.1 & $\begin{array}{c}(158-194) \\
182 \pm 2.1\end{array}$ & 4.3 & $\begin{array}{c}(182-211) \\
198 \pm 4.3\end{array}$ & 4.5 & $\begin{array}{c}(1,758-2,073) \\
1,860 \pm 6,9\end{array}$ & 8,7 \\
\hline & \multicolumn{3}{|c|}{ Average } & $108 \pm 1$ & 4.1 & $183 \pm 2.2$ & 4.4 & $200 \pm 4.2$ & 5.1 & $1,890 \pm 7.1$ & 8.2 \\
\hline \multirow{3}{*}{2} & 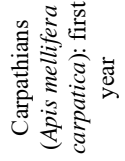 & 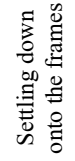 & $\begin{array}{l}\bar{\Xi} \\
\text { Jूँ } \\
\text { ¿ }\end{array}$ & $\begin{array}{l}(95-113) \\
106 \pm 1.4\end{array}$ & 3.9 & $\begin{array}{c}(143-191) \\
182 \pm 2.4\end{array}$ & 4.1 & $\begin{array}{c}(174-216) \\
196 \pm 5.4\end{array}$ & 4.8 & $\begin{array}{c}(1,612-1,973) \\
1,800 \pm 7,8\end{array}$ & 9,3 \\
\hline & 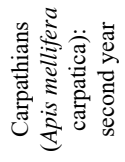 & 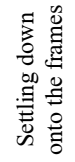 & 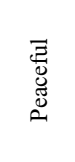 & $\begin{array}{l}(93-112) \\
104 \pm 1.5\end{array}$ & 3.5 & $\begin{array}{c}(142-189) \\
180 \pm 2.3\end{array}$ & 4.3 & $\begin{array}{c}(176-209) \\
194 \pm 4.9\end{array}$ & 5.4 & $\begin{array}{c}(1,586-1,951) \\
1,740 \pm 7,4\end{array}$ & 6,7 \\
\hline & & $a^{g}$ & & $105 \pm 1.4$ & 3.7 & $181 \pm 2.3$ & 4.2 & $195 \pm 5.2$ & 5.1 & $1,770 \pm 7.9$ & 8 \\
\hline
\end{tabular}

As can be seen from the diagram above, the Carniolan breed was found to be $98.1 \%$ effective per day, $98.95 \%$ per day unfertilized, $97.5 \%$ fertilized, and $98.3 \%$ effective per day according to the standard measure. In Carpathian bees, the daily rate was $95.4 \%$, unfertilized $97.8 \%$, fertilized $95.1 \%$, and daily egg laying was $97.5 \%$.

\subsection{Results of beekeeping of Carniolan (Apis mellifera carnica Pollm) and Carpathian (Apis mellifera carpatica) bees in experimental groups}

Beekeeping of bee families is carried out during the autumn inspection of bees (September-October). Families of bees that have had a healthy winter and participated in honey collection in the year of beekeeping are eligible for beekeeping. In the year of creation of the breeding nucleus in the brand beekeeping, all bee families are evaluated. Data on the breeding, honey yield, strength and winter hardiness of bee families are collected throughout the year [3]. 
The chief zootechnician and experienced beekeepers of Kibray district took part in our scientific research in the evaluation of bee families. Before the start of indexing the quality of soil, the zootechnical accounting data of the farm (based on the entries in the accounting journal of the beekeeping farm) were studied.

The spring and autumn inspection reports (acts) of the farm, as well as the number of beehives were identified. Beekeeping of bee families in the experimental groups was carried out annually in October, when the air temperature was $+16^{\circ} \mathrm{C}$ on a day without precipitation during the autumn inspection.

During the evaluation, the bees in the experimental groups were evaluated on the pedigree (exterior and biological indicators) of the bee families and on three main indicators, namely, honey yield, family strength and winter hardiness. The total honey yield of bee families in the experimental groups (the commodity obtained and the amount of feed honey left for the winter in the hive) was studied.

The amount of honey in the mummified frames was determined by weighing the empty mummified frames $(0.5-0.6 \mathrm{~kg})$ by weighing them on a scale. Honey productivity is expressed as a percentage of the total amount of honey collected by bee families in experimental groups to the average honey yield of bee families on the farm in the year of evaluation and determined using the following equation (1) [3]:

$$
M P=\frac{M P \times 100}{S M P P}
$$

Where, MP - Gross Honey Productivity; and SMPP - average honey yield of common bee families on the farm in the year of indexing the soil quality.

The strength of the bee families was assessed before the main honey collection season, which was determined by counting the number of frames occupying both sides of the beehives. If necessary, the egg productivity of queen bees was determined before the main honey harvest season. To do this, the area of the sealed offspring (eggs laid) of the mummies in the frames occupying both sides of the beehives was measured. A $5 \times 5 \mathrm{~cm}$ frame (100 square inches per square inch) was used for the measurement.

Winter hardiness of bee families was assessed on the winter expenditure of bees using the data of autumn and spring inspection (act) acts of the beekeeping. The winter expenditure of bee families is calculated as the percentage of the number of frames occupied by bees in the hive before the winter, the number of frames occupied by bees in the hive after the winter, and its percentage is determined by the following equation (2) [3, 7]:

$$
Z O P=\frac{C H S-P Z \times 100}{C H S}
$$

Where, ZOP - winter expenditure of bee families; CHS - number of frames occupied by bees in the propolis mummies before winter; and, PZ - number of rum occupied by bees in the propolis mummies after winter.

The results in the experimental groups showed that Carniolan (Apis mellifera carnica Pollm) bees produced $58.6 \pm 0.9 \mathrm{~kg}$ of honey in the first year compared to the Carpathian (Apis mellifera carpatica) breed in terms of gross honey yield (commodity obtained and amount of feed honey left for winter in the hive) or $7.9 \%$, in the second year $56.3 \pm 1.2 \mathrm{~kg}$ or $7.4 \%$ more gross honey was collected. The two-year average honey yield was $57.4 \pm 1$ $\mathrm{kg}$ or $10.7 \%$ higher $(\mathrm{R}>0.999)$. 5 points were given for gross honey yield (Table 2 ). 
Table 2. Results of beekeeping in experimental groups (n-50)

\begin{tabular}{|c|c|c|c|c|c|c|c|c|c|c|c|}
\hline \multirow[b]{2}{*}{ 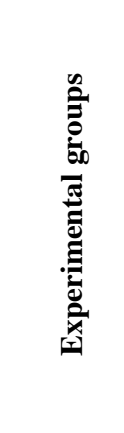 } & \multirow[b]{2}{*}{ 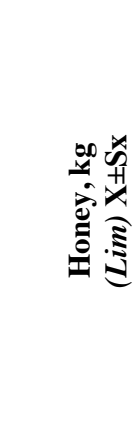 } & \multirow{2}{*}{ 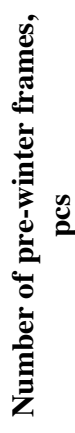 } & \multirow{2}{*}{ 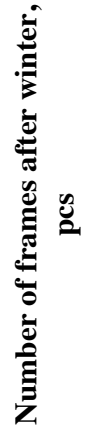 } & \multirow{2}{*}{ 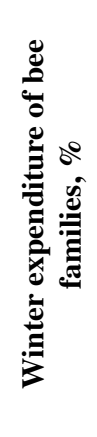 } & \multicolumn{6}{|c|}{ Important aspects, pts } & \\
\hline & & & & & 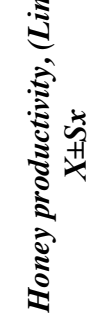 & $\vec{b}$ & 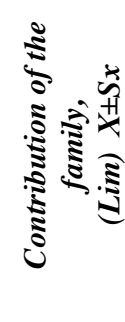 & $\begin{array}{l}\vdots \\
\dot{0}\end{array}$ & 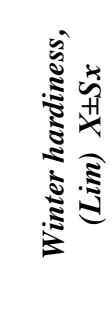 & $\begin{array}{l}\vdots \\
\dot{0}\end{array}$ & $\frac{\tilde{\sigma}}{0}$ \\
\hline 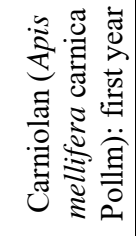 & $\begin{array}{c}(48.4- \\
63.1) \\
58.6 \pm 0.9\end{array}$ & 8 & 7 & 12.5 & $\begin{array}{c}(3-8) \\
5 \pm 0.1\end{array}$ & 0.4 & $\begin{array}{c}(4-9) \\
5 \pm 0.3\end{array}$ & 0.2 & $\begin{array}{l}(2-6) \\
4 \pm 0.1\end{array}$ & 0.1 & 2 \\
\hline 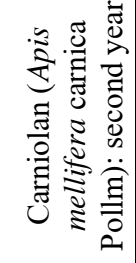 & $\begin{array}{c}(46.2- \\
59.4) \\
56.3 \pm 1.2\end{array}$ & 8 & 7.5 & 6.25 & $\begin{array}{c}(4-9) \\
5 \pm 0.1\end{array}$ & 0.7 & $\begin{array}{l}(2-6) \\
4 \pm 0.2\end{array}$ & 0.6 & $\begin{array}{c}(4-9) \\
5 \pm 0.3\end{array}$ & 0.3 & 2 \\
\hline Average & $57.4 \pm 1$ & 16 & 14.5 & 9.37 & $5 \pm 0.1$ & 0. & $4.5 \pm 0.2$ & 0.4 & $4.5 \pm 0.2$ & 0.2 & 2 \\
\hline 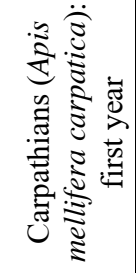 & $\begin{array}{c}(43.6- \\
58.5) \\
54.3 \pm 0.8\end{array}$ & 8 & 6.5 & 18.75 & $\begin{array}{c}(3-9) \\
5 \pm 0.2\end{array}$ & 0.4 & $\begin{array}{l}(2-7) \\
4 \pm 0.3\end{array}$ & 0.6 & $\begin{array}{c}(2-5) \\
3 \pm 0.1\end{array}$ & 0.2 & 4 \\
\hline 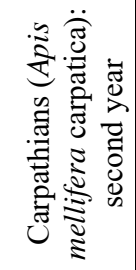 & $\begin{array}{c}(42.8- \\
57.3) \\
52.4 \pm 0.7\end{array}$ & 8 & 7 & 12.5 & $\begin{array}{l}(4-9) \\
5 \pm 0.3\end{array}$ & 0.2 & $\begin{array}{c}(4-8) \\
5 \pm 0.2\end{array}$ & 0.4 & $\begin{array}{l}(3-6) \\
4 \pm 0.2\end{array}$ & 0.1 & 2 \\
\hline Average & $53.3 \pm 0.8$ & 16 & 13.5 & 15.62 & $5 \pm 0.2$ & 0.3 & $4.5 \pm 0.2$ & 0.5 & $3.5 \pm 0.1$ & 0.2 & 3 \\
\hline
\end{tabular}


The strength of the family was assessed by the egg productivity at which the queen put the bees on the rum before the main honey collection season. In this case, depending on the number of closed offspring placed on the frame of $435 \times 300 \mathrm{~mm}$ for 10 frames, $5 \pm 0.3$ points in the first year, $4 \pm 0.2$ points in the second year, $4.5 \pm 0.2$ points on the strength of the two-year average family $(\mathrm{R}>0.999)$.

Winter hardiness was rated at $4 \pm 0.1$ points in the first year, $5 \pm 0.3$ points in the second year, and $4.5 \pm 0.2$ points on the two-year average winter hardiness $(\mathrm{R}>0.999)$. There are 2 categories on the rating scale.

Carpathian bee breed with a two-year gross honey yield of $53.3 \pm 0.8 \mathrm{~kg}$ of honey with 5 points, family strength with $4.5 \pm 0.2$ points, winter hardiness with $3.5 \pm 0.1$ points rated on 3 scales.

It should be noted that in the rating of bees, categories 1-8 are assigned. Bee families with a score higher than 8 categories are rejected.

\section{Conclusion}

According to the results of the study, bees of the genus Carniolan (Apis mellifera carnica Pollm) and Carpathians (Apis mellifera carpatica) imported from abroad were found to have a longer period of rapid growth and development of the family in the spring. It has been proven to be effective in collecting juice from different types of plants, low susceptibility to roe, high production of wax products and high ability to turn juice into wasted honey, not peaceful and aggressive. Due to its high productivity, resistance to any weather, good adaptation to our climatic conditions and other advantages, it is advisable to use bees of the genus Carniolan (Apis mellifera carnica Pollm) and Carpathian (Apis mellifera carpatica) in beekeeping.

\section{References}

1. Presidential Decree No. 3327 of the Republic of Uzbekistan 'On measures to further develop the beekeeping industry in the country', October 16 (2017)

2. N. M. Abdulgazina, Biological features of honey productivity and winter hardiness of Burzyan bee (apis mellifera mellifera l.) (PhD dissertation, Moscow, 2016)

3. N. L. Burenin, G. N. Kotova, Bee rating (Moscow, 1984)

4. G. D. Bilash, Bee breeding (Agropromizdat, Moscow, 1991)

5. V. A. Gaydar, Beekeeping 9, 24-26 (2006)

6. V. A. Gaydar, Fishery, 115-120 (2003)

7. SH. R. Suyarkulov, Beekeeping 6, 13-15 (2010)

8. M. Kovačić, Z. Puškadija, M. M. Dražić, A. Uzunov, M. D. Meixner, R. Büchler, Apidologie 51(6), 1062-1073 (2020)

9. O. S. Turaev, A. Avizov, A. Atleumuratov, A. Kaplun, Zooveterinary 4, 44-45 (2013)

10. Z. H. Ahmed, A. I. Tawfik, M. F. Abdel-Rahman, A. M. Moustafa, Bee World 97(1), 26-31 (2020)

11. F. G. Yumaguzhin, Agrarian Sciences 12, 18-20 (2012)

12. R. A. Ilyasov, Bees for development 114, 11-17 (2015)

13. R. A. Ilyasov, The Four Seasons 55, 27-32 (2015) 